\title{
A Sonic-Flow Pyrometer for Measuring Gas Temperatures
}

\author{
George T. Lalos
}

\begin{abstract}
Evaluation of the performance of gas turbines and jet engines requires knowledge of the temperature of the working medium. Although conventional temperature-measuring instruments are adequate for some purposes, they possess a number of disadvantages that become more serious with increasing gas velocity and temperature. The most troublesome sources of error are the directed motion of the gas and the loss of heat to the surroundings by radiation and conduction. An instrument that is relatively free of these errors is described and evaluated. It has been called a sonic pyrometer because the measuring element is located in the throat of a nozzle through which the gas, whose temperature is to be measured, is caused to flow at sonic velocity. In accordance with theory and experiment, the total temperature of the gas is obtained by multiplying the temperature indicated by the measuring element by an essentially constant correction factor. Tests on experimental units indicate that these have many advantages over conventional instruments when used in the evaluation and control of gas turbines and jet engines.
\end{abstract}

\section{Introduction}

While conventional instruments for measuring the temperature of the working medium of gas turbines and jet engines are adequate for some purposes, they have certain inherent disadvantages that become more serious with increasing gas temperature and velocity. Particularly troublesome are the effects on temperature-sensing elements of directed motion of the gas and of heat loss to the surroundings by radiation and conduction.

As will be shown, these effects become negligibly small in an instrument of the type described. In such an instrument the measuring junction of a thermocouple is located within the throat of a small nozzle, through which the gas whose temperature is to be measured is caused to flow at sonic velocity. For the latter reason, such a modification of the familiar suction pyrometer is here called a sonic pyrometer.

When the velocity of the gas in the free-stream exceeds a few hundred feet per second, the kinetic energy of directed motion becomes an appreciable fraction of that due solely to random molecular motion. For a complete energy accounting under these conditions it is therefore necessary to recognize two temperatures, pressures, and enthalpies in specifying the energy state of the moving gas. These are frequently identified by the adjectives static and total. As an example, the static temperature would be indicated by an error-free thermocouple moving in the same direction and at the same velocity as the gas, that is, by one that is static with respect to the gas; the total temperature would be indicated by an error-free instrument immersed in the gas fter the latter is brought to rest adiabatically.

1 The material contained in this report has been accepted by the Catholic University of America in partial fulfillment of the requirements for the degree of Master of Science in Physies.
The relation between these two temperatures of a flowing gas can be expressed by the well-known equations

and

$$
T_{t}-T_{s}=V^{2} / 2 g J C_{p},
$$

$$
T_{t} / T_{s}=1+(\gamma-1) M^{2} / 2,
$$

in which $T$ is absolute temperature $\left({ }^{\circ} \mathrm{R}\right), V$ is velocity $(\mathrm{ft} / \mathrm{sec}), g$ is the acceleration of gravity $\left(\mathrm{ft} / \mathrm{sec}^{2}\right), J$ is the mechanical equivalent of heat ( $\mathrm{ft} \mathrm{lb} / \mathrm{Btu}), C_{p}$ is heat capacity at constant pressure (Btu/lb deg R), $\gamma$ is the specific heat ratio, $M$ is Mach number, and the subscripts $s$ and $t$ signify static and total, respectively.

When an error-free, conventional temperaturesensing instrument is immersed in a flowing gas, it reaches and indicates a temperature $\left(T_{i}\right)$ intermediate between $T_{t}$ and $T_{s}$. Neither $T_{t}$ nor $T_{s}$ can be deduced from an observed value of $T_{i}$ without further knowledge of the characteristics of the instrument.

Experiments have shown that each actual instrument, in the absence of other errors, attains a temperature that exceeds $T_{s}$ by a nearly constant fraction of the interval $T_{t}-T_{s}$. This fraction, known as the recovery factor $(r)$, is a function of the configuration of the instrument and changes little with the composition, temperature, pressure, or velocity of the flowing gas. The above definition of recovery factor is expressed by the equation

$$
r=\left(T_{i}-T_{s}\right) /\left(T_{t}-T_{s}\right) .
$$

Combining eq 1 and 3 gives

$$
T_{t}=T_{i}+(1-r) V^{2} / 2 g J C_{p},
$$

from which it is seen that the actual temperature of a high-velocity gas stream can be calculated from the 
temperature indicated by a conventional instrument only when the velocity and heat capacity of the gas and the recovery factor of the instrument are known. This requirement obviously constitutes a serious limitation to the application of conventional sensing elements at high gas velocities.

It is to be noted that the higher the recovery factor of the instrument, the smaller is the difference between $T_{i}$ and $T_{t}$, and the less is the need for accuracy in the values of $V$ and $C_{p}$. Total-temperature probes, which indicate $T_{t}$ directly, are in common use in the low-temperature range. However they are not practical at high temperatures and under the extreme mechanical stresses existing in gas turbines. Nevertheless, an instrument designed for engine applications should have the highest practicable recovery factor.

Conventional instruments have a second limitation that can be understood by considering the heat transfer to and from the surroundings. In most applications, the gas turbine being a common one, the retaining walls are colder than the gas. A measuring instrument immersed in the stream thus attains a steady temperature below that of the gas, because energy is lost by the sensing element to the walls by radiation and conduction. The temperature indicated by the element is determined by the relative rates of heat transfer from the gas by forced convection and to the surroundings by radiation and conduction. The heat exchange with the surroundings is a function of the temperatures of the element and the walls, and that part that is due to radiation increases approximately as the fourth power of the gas temperature. From the standpoint of thermometric error, it is obviously desirable that the rate of transfer to the element be high as compared with the rate of loss.

For a conventional element installed in a gas turbine, no independent control can be exercised over the mass rate at which gas flows over the instrument, which in turn determines the rate of heat transfer to the unit by forced convection. Actually this rate is a function of the operating conditions alone, and these, for aircraft gas turbines, involve flow rates that decrease with altitude. Thus, although the error of a conventional instrument due to radiation and conduction could be reduced by increasing the mass flow past the sensing element, not only is it impossible to exercise such control in an engine, but also the accuracy of the measured temperatures decreases with decreasing ambient pressure (i. e. with increasing altitude).

From the above facts, it is clear that improved performance and simplified over-all instrumentation may be possible by modifying conventional sensing elements so that (a) the recovery factor is increased; (b) the rate of heat loss from the sensing element by radiation and conduction is decreased; (c) the mass flow across the element is as high as practicable; and (d) the temperature indicated is independent of the free-stream velocity.

It will be shown that a sonic pyrometer can be designed to have most of these advantages, and that it therefore deserves careful consideration in the instrumentation of gas turbines. Previous reports on the sonic pyrometer appeared as classified documents, and more recently a paper published by Allen and Hamm [1] described one instrument of this type. The present detailed study was undertaken because none of the previous reports contain a careful evaluation of the several important design variables.

The present results, obtained with three experimental units, are in excellent agreement with theory, and indicate that a single calibration in air at a relatively low temperature, together with a knowledge of the $\gamma$ of the gas in which the instrument is applied, suffices for calculating reliable values of $T_{t}$ from observed values of $T_{i}$ over the range experienced in gas turbines.

\section{Theory of the Sonic Pyrometer}

Sonic gas velocity $\left(V_{c}\right)$ is always maintained over the measuring junction of the sonic pyrometer. This velocity may be expressed as follows in terms of the properties and state of the gas:

$$
V_{c}^{2}=\gamma g R T_{s}
$$

in which $R$ is the gas constant in $\mathrm{ft} \mathrm{lb} / \mathrm{lb} \mathrm{deg}$ Rankine, and the other quantities have been defined previously.

Since $C_{p}-C_{v}=R / J$, eq 1 and 5 under conditions of sonic flow may be combined to give

$$
T_{s}=2 T_{t} /(\gamma+1) .
$$

Combining eq 4, 5, and 6 gives

$$
T_{t}=(\gamma+1) T_{i} /[2+r(\gamma-1)]=\alpha T_{i},
$$

where $\alpha=(\gamma+1) /[2+r(\gamma-1)]$.

Calibration and use of the sonic pyrometer would be extremely simple if the $\alpha$ of a given instrument were completely independent of operating conditions. This cannot be so, because $\gamma$ decreases somewhat with increasing temperature. Application of the instrument remains relatively simple if $r$ is sensibly constant, even though the effect of changing $\gamma$ must be taken into account. It is to be noted that both $\alpha$ and $r$ approach unity simultaneously, and that the dependence of $\alpha$ upon $\gamma$ becomes vanishingly small as $r$ approaches unity.

To illustrate these points, assume that a sonic pyrometer, for which $\alpha$ has been determined by using air having a $\gamma=1.400$, is applied in highvelocity streams of air at elevated temperatures, and that the latter temperatures are calculated by multiplying each observed value of $T_{i}$ by the same constant $\alpha$. Under the calibration conditions, $\alpha$ is simply the ration $T_{t} / T_{i}$, of two measured quantities, and since the $\gamma$ of the calibrating air is 1.400 ,

$$
\alpha=6 /(5+r) \text {. }
$$

This $\alpha$ is not exactly correct at any other tempera- 

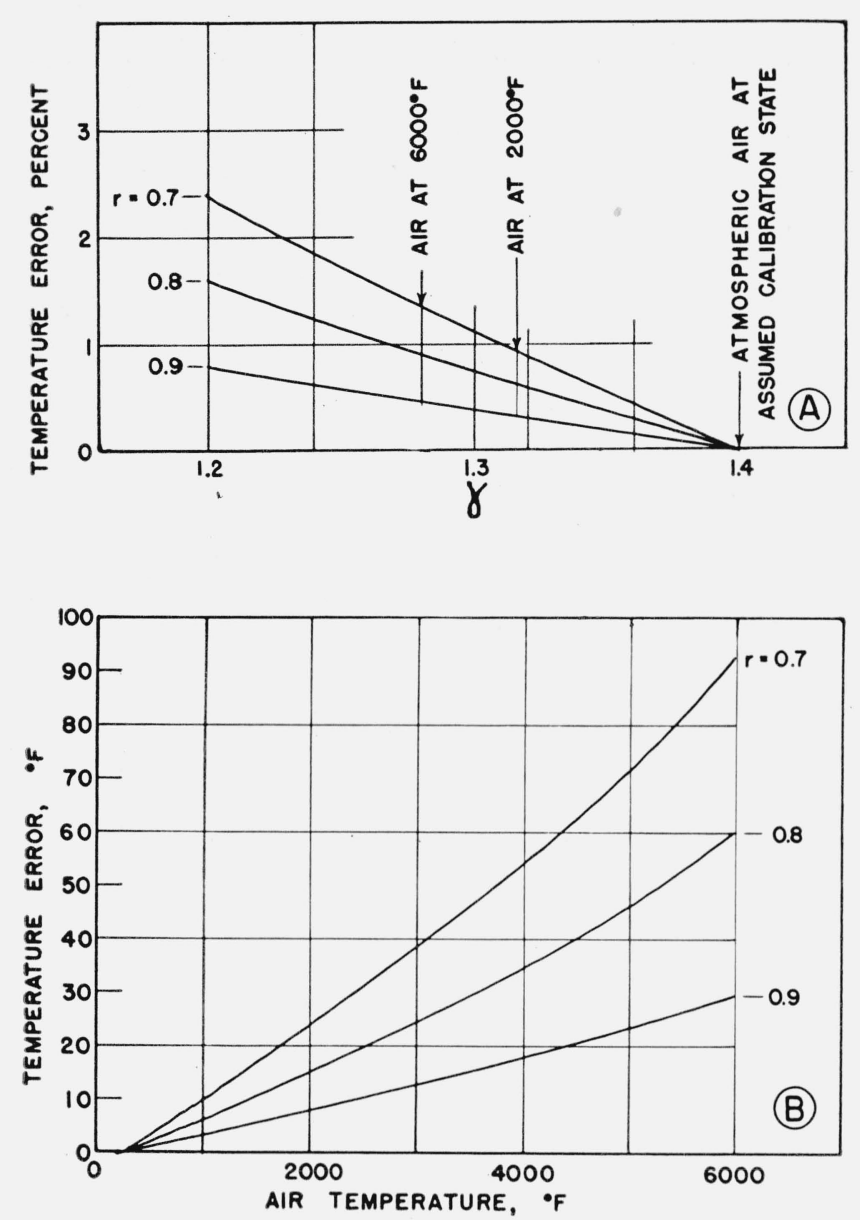

FiguRE 1. Temperature errors that arise if the variation of $\gamma$ with temperature is neglected, as calculated for sonic pyrometers having various values of recovery factor, $r$.

ture, and from eq 7 and 8 the fractional error, $E$, of each observed value of $T_{t}$ due to deviations in $\gamma$ from the calibration value of 1.400 is

$$
E=\frac{(r-1)(5 \gamma-7)}{(r+5)(\gamma+1)}
$$

Such errors, expressed in percentage, are plotted in figure $1, \mathbf{A}$, as funcions of $\gamma$ at assumed constant values of $r$ over the range of the latter, which is to be expected from a thermocouple junction in a sonic pyrometer. Using tabulated values of the $\gamma$ of air as a function of temperature [2], the percentage errors can be interpreted in terms of absolute error, as has been done in figure 1,B. It can be seen that changes in $E$ due to changes in $r$ and in $\gamma$ are small, and that it is desirable to make $r$ as high as is practicable.

In the preceding example it has been assumed that the recovery factor of a given instrument has the same value, $r=6 / \alpha-5$, during the calibration and in actual use. If this assumption is correct, then the errors discussed in the foregoing example can be avoided as follows: In a calibration under convenient conditions (as with air at a relatively low temperature), determine $r$ as $6 T_{i} / T_{t}-5$; apply the instrument in any gas, and calculate $T_{t}$ from eq 7 , using the actual value of $\gamma$ and the experimental value of $r$. One of the purposes of the present tests was to determine whether such a procedure was permissible with the sonic pyrometer.

It is to be expected that the recovery factor of a bare thermocouple junction located in a sonic stream and obstructing only a small fraction of the flow area will approach the theoretical value for a flat plate, which, according to Pohlhausen [3], and more recently to Emmons and Brainerd [4], approaches 0.87. Another purpose of the present tests was to determine how closely this theoretical value could be approached in a practical sonic pyrometer.

\section{Apparatus and Results}

Three experimental sonic pyrometers, designated as 1,2 , and 3 , were built and evaluated. Unit 1 was designed for low temperatures only, with the idea that it would yield enough information to determine whether the construction of more elaborate instruments seemed worth while. Unit 2 was built for use up to $1,500^{\circ} \mathrm{F}$, but without regard to its suitability for use in gas turbines, particularly as to its size. Unit 3 was designed on a smaller scale, and its performance was investigated in much greater detail than was that of the other two.

The calibration equipment, with the No. 1 unit mounted for test, is shown diagrammatically in figure 2. The sole purpose of the pressure taps was for initial evaluation of nozzle performance and to insure that the flow was sonic at station 2 during use. The flow area at station 1 was so large that the impact effect was negligible, and the thermocouple there served for the accurate measurement of $T_{1 s}=T_{11}$. From this chamber the gas passed to the nozzle of the sonic pyrometer and was accelerated to sonic velocity at station 2 by maintaining the ratio $P_{2 s} / P_{1 s}$ always below the required critical value. This could be done in the test system either by compressing to increase $P_{1 s}$, or by pumping to reduce $P_{2 s}$. Since it would complicate a service instrument to install a pressure tap at the throat of the nozzle, a second downstream pressure tap was installed at station 3 . If the flow area between stations 2 and 3 is made large as compared with the area of the throat, the pressures at these two stations are approximately equal, and only the tap at station 3 is needed. It is further advantageous to keep the pressure drop between stations 2 and 3 small in order that sonic flow may be maintained with a minimum of pressure at station 1 during discharge to the atmosphere or with a minimum of pumping on the discharge of the unit.

In tests at room temperature the heat loss between stations 1 and 2 is entirely negligible. Since air behaves nearly as a perfect gas, there is no change in total temperature between these stations, so that $T_{2 t}$ is identical with the measured $T_{1 t}$. The calibration value of $\alpha$ is simply the ratio of the observed 


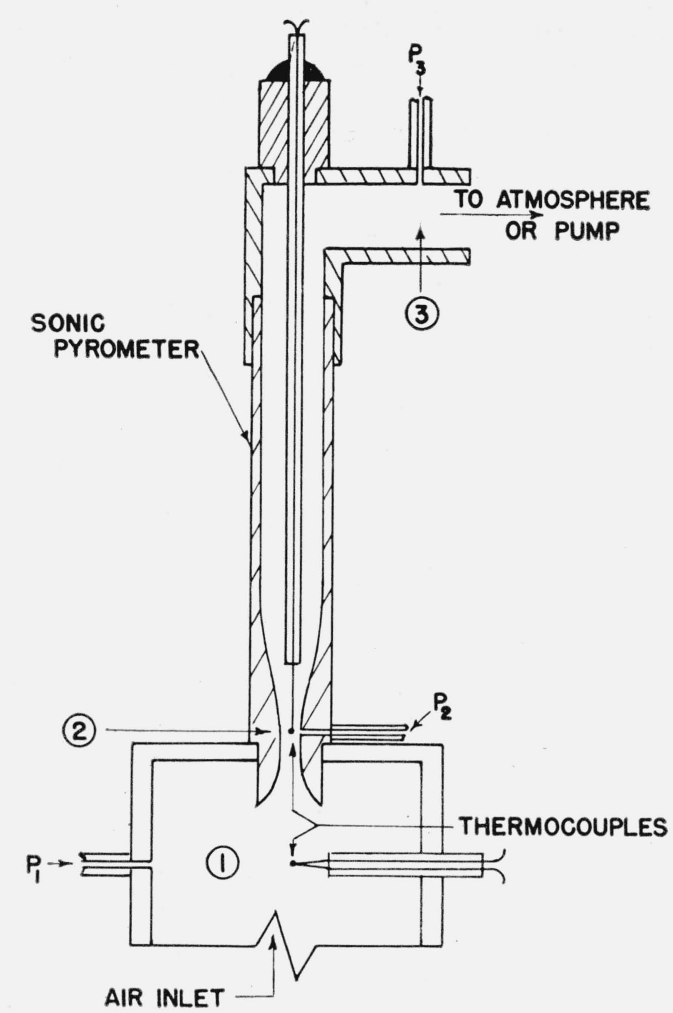

Figure 2. Diagram of calibration equipment with sonic pyrometer 1 mounted for test.

quantities $T_{1 t}=T_{2 t}$ and $T_{2 i}$. The recovery factor of the unit is $6 / \alpha-5$ when the $\gamma$ of the calibrating air is 1.400 .

\subsection{Experimental Sonic Pyrometer 1}

The first unit, designed for preliminary studies at temperatures below $400^{\circ} \mathrm{F}$ and shown in cross section in figure 2, had a convergent-divergent brass inlet nozzle with a cylindrical throat three-eighths in. long and 0.165 in. in diameter. A bare thermocouple junction of No. 28 gage Chromel and Alumel wire was located centrally at the downstream end of the throat (station 2), directly alongside a static pressure tap. The junction itself was approximately spherical and had a diameter about twice that of either thermocouple wire. An identical thermocouple was installed at station 1 in a comparatively large inlet chamber, for the measurement of $T_{1 t}=\dot{T}_{1 s}=T_{2 t}$. The static pressures in the inlet chamber, nozzle throat, and exit passage were measured with mercury manometers.

Air supplied to the inlet chamber could be maintained by electric heaters at any desired steady temperature in the range from room temperature to $400^{\circ} \mathrm{F}$. Thermal electromotive forces were measured with a semiprecision potentiometer. Sonic flow through the nozzle could be maintained either by establishing the necessary pressure in the inlet chamber and discharging into the atmosphere, or by pumping at the exit when required.
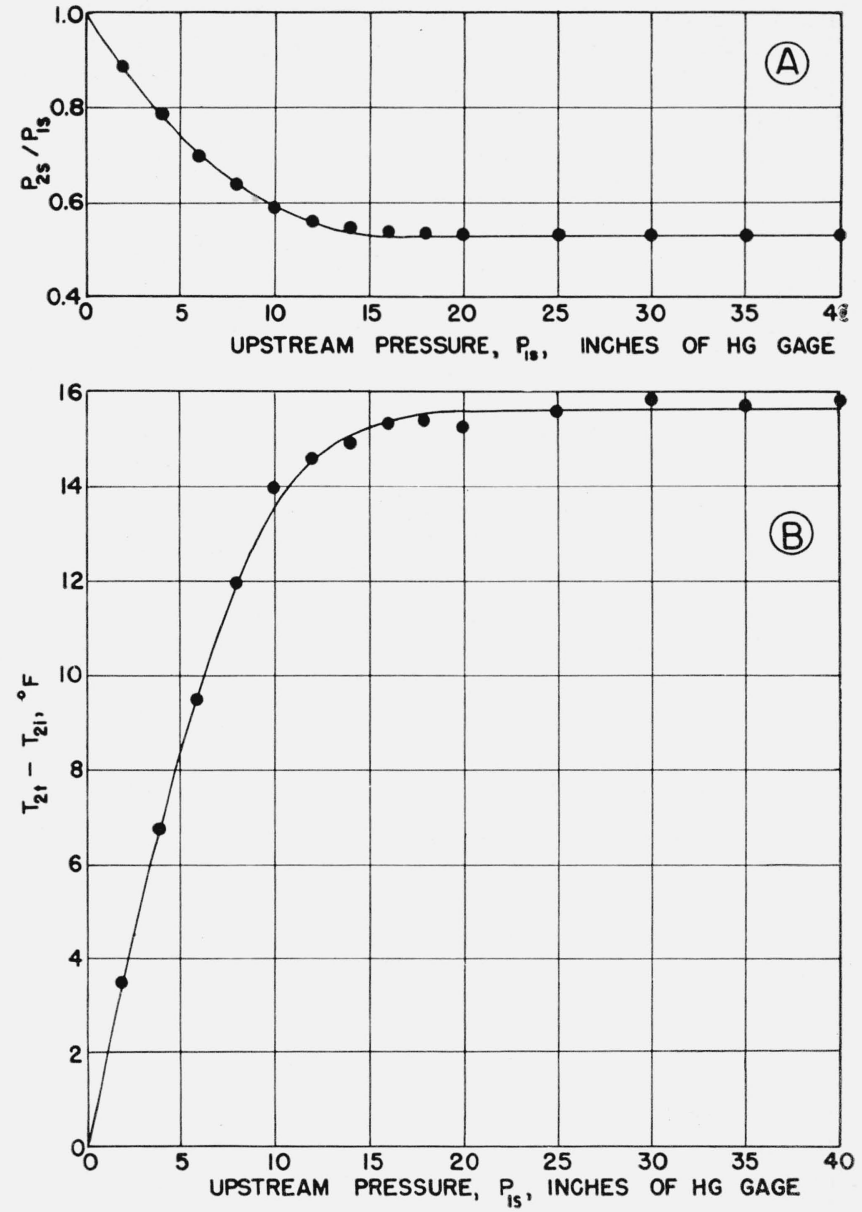

Figure 3. Performance of sonic pyrometer 1 .

The characteristics of the instrument, as determined with atmospheric air $\left(74^{\circ} \mathrm{F} ; \gamma=1.400\right)$ and with $P_{3 s}=1 \mathrm{~atm}$ are shown in figure 3 . Figure $3, \mathrm{~A}$, in which the pressure ratio $P_{2 s} / P_{1 s}$ is plotted against $P_{1 s}$ in inches of mercury gage, shows that the nozzle of the pyrometer behaves in accordance with theory, since $P_{2 s} / P_{1 s}$ attains a constant value of 0.53 . A $\mathrm{At}$ all values of $P_{1 s}$ greater than $20 \mathrm{in.} \mathrm{mercury} \mathrm{gage,}$ the flow is therefore sonic in the throat, and the desired condition for the operation of the pyrometer prevails. In figure $3, \mathrm{~B}$, the observed difference in temperature $T_{2 t}-T_{2 i}$ is plotted against upstream static pressure. Again in accordance with theory, this difference increases with the velocity in the throat (i. e. with increasing $P_{1 s}$ ) until this velocity becomes sonic at $P_{1 s}=20$ in. mercury gage. For all higher values of $P_{1 s}$, the total and indicated temperatures of the gas in the throat of the nozzle remain constant and differ by $15.6 \mathrm{deg} \mathrm{F}$. The measured values of $T_{2 t}=533.7^{\circ} \mathrm{R}$ and $T_{i}=518.1^{\circ} \mathrm{R}$ constitute a calibration of the unit. Inserting these values, and $\gamma=1.400$, in eq 7 gives $\alpha=1.030$ and $r=0.825$.

In all experiments of this type, the thermocouples at stations 1 and 2 were made from adjacent lengths of wire to avoid possible errors from inhomogeneities. The emfs of the thermocouples were always read 
individually and by bucking one against the other (i. e. differentially), and in no case did the observed difference in temperature depart more than $0.1 \mathrm{deg}$ $\mathrm{F}$ from that obtained by subtraction.

Using eq 7 , the results may be computed in the following ways: (a) on the assumption that $\alpha$ always has the same value as that determined in the calibration run; (b) on the assumption that $r$ always has the same value as that determined in the calibration run, but that $\alpha$ varies with $\gamma$; or (c) the appropriate values of $T_{2 t}, \mathrm{~T}_{2 i}$, and $\gamma$ may be used in solving for a value of $r$ for each run. Table 1 summarizes the data for four runs made at initial temperatures of $74^{\circ}$ (calibration), $279.0^{\circ}, 395^{\circ}$, and $400^{\circ} \mathrm{F}$, and of results calculated on the aforementioned bases. The next to the last column gives values of the static temperature $\left(T_{2 s}\right)$ in the nozzle throat, calculated from eq 2 for the condition of sonic flow, that is, when $M=1$.

The tabulated values show that the sonic pyrometer gives values of the total temperature of the high-velocity air that differ in no case from the value observed before the air is accelerated by more than $0.6 \mathrm{deg} \mathrm{F}$, regardless of the assumptions made as to $\alpha$ and $\gamma$, and despite increasing differences between

TABLE 1. Results obtained with sonic pyrometer 1

\begin{tabular}{|c|c|c|c|c|c|c|c|c|c|c|c|}
\hline \multirow{2}{*}{$\begin{array}{l}\text { Run } \\
\text { No. }\end{array}$} & \multicolumn{2}{|c|}{$\begin{array}{l}\text { Observed tem- } \\
\text { peratures }\end{array}$} & \multirow{2}{*}{$\begin{array}{l}\gamma \text { from } \\
\text { tables }\end{array}$} & \multirow{2}{*}{$\begin{array}{c}T_{2 t}^{\prime} \text { (calc), } \\
\text { assuming } \\
\alpha=1.030\end{array}$} & \multirow{2}{*}{$\begin{array}{l}T_{2 t}-T_{2 t}^{\prime} \\
\text { (cale) }\end{array}$} & \multirow{2}{*}{$\begin{array}{c}T_{2 t}^{\prime \prime}(\text { calc }), \\
\text { assuming } \\
r=0.825\end{array}$} & \multirow{2}{*}{$\begin{array}{c}T_{2 t}-T_{2 t}^{\prime \prime} \\
\text { (calc) }\end{array}$} & \multirow{2}{*}{$\begin{array}{l}r, \text { from } \\
\text { eq } 7\end{array}$} & \multirow{2}{*}{$\begin{array}{l}\text { Deviation } \\
\text { from mean } \\
r\end{array}$} & \multirow{2}{*}{$\begin{array}{l}T_{2 s}, \text { from } \\
\quad \text { eq } 2\end{array}$} & \multirow{2}{*}{$T_{2 t}-T_{2 s}$} \\
\hline & $T_{2 t}$ & $T_{2 i}$ & & & & & & & & & \\
\hline $\begin{array}{r}a 1 \\
2 \\
3 \\
4\end{array}$ & $\begin{array}{c}{ }^{\circ} R \\
533.7 \\
738.7 \\
854.7 \\
859.7\end{array}$ & $\begin{array}{c}{ }^{\circ} R \\
518.1 \\
717.0 \\
830.4 \\
834.8\end{array}$ & $\begin{array}{l}\text { 1. } 400 \\
1.395 \\
1.388 \\
1.388\end{array}$ & $\begin{array}{c}{ }^{\circ} R \\
533.7 \\
738.5 \\
855.3 \\
859.8\end{array}$ & $\begin{array}{c}{ }^{\circ} R \\
0.0 \\
.2 \\
-.6 \\
-.1\end{array}$ & $\begin{array}{c}{ }^{\circ} R \\
533.7 \\
738.3 \\
854.7 \\
859.2\end{array}$ & $\begin{array}{c}\circ R \\
0.0 \\
.4 \\
.0 \\
.5\end{array}$ & $\begin{array}{r}0.825 \\
.822 \\
.825 \\
.822\end{array}$ & $\begin{array}{c}\text { Percent } \\
+0.2 \\
-.2 \\
+.2 \\
-.2\end{array}$ & $\begin{array}{c}{ }^{\circ} R \\
444.8 \\
616.9 \\
715.8 \\
720.0\end{array}$ & $\begin{array}{c}{ }^{\circ} R \\
88.9 \\
121.8 \\
138.9 \\
139.7\end{array}$ \\
\hline & & & & & & & Mean.... & $0.823_{5}$ & & & \\
\hline
\end{tabular}

a Calibration run, giving $\alpha=1.030$ and $r=0.825$.

$T_{2 t}$ and $T_{2 s}$. The calculated values of recovery factor are sensibly constant, the maximum deviation from the mean value of $r$ being only 0.2 percent.

Although the range of temperatures used in the tests described is very small, the tabulated results were believed to indicate that unit No. 1 showed sufficient promise to warrant the construction and evaluation of more practical units, designed for higher temperatures.

\subsection{Experimental Sonic Pyrometer 2}

In this unit, shown photographically in figure 4 and schematically in figure 5, the nozzle and support-
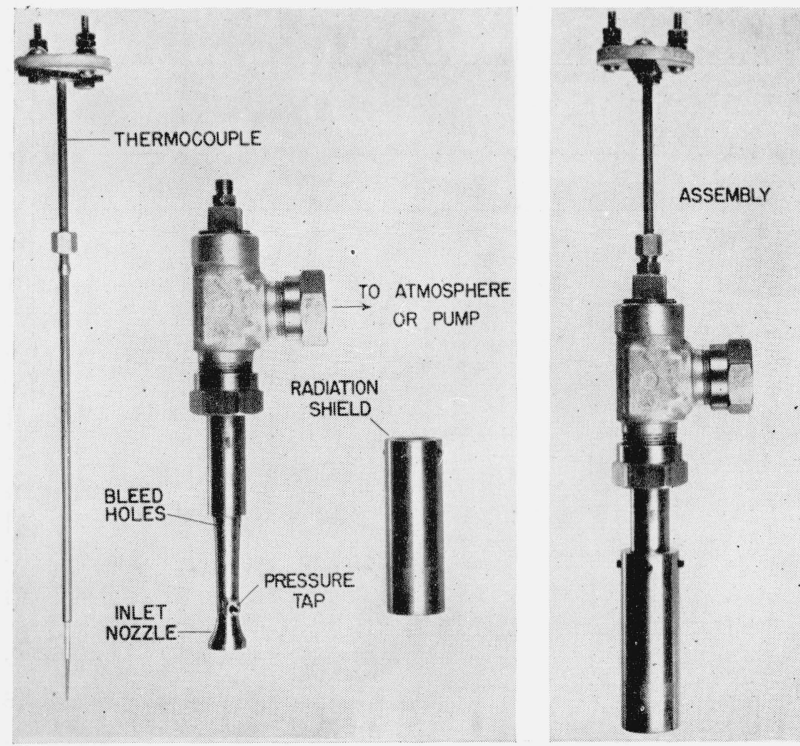

FiguRE 4. Sonic pyrometer 2. ing parts were made of 18-8 stainless steel, and the nozzle was surrounded by an outer tube $\left(1 \frac{1 / 8^{-}}{}\right.$in. outside diameter), which served as a radiation shield. To aid in bringing both the nozzle and its shield to the gas temperature, gas was brought to stagnation in the space between these parts, and small bleed holes were provided to renew this stagnant gas slowly.

The throat of the nozzle had a diameter of 0.21 in. and was cylindrical for a length of three-eighths in. A pressure tap in the throat was used only in preliminary tests made to show that sonic flow was attained at all pressure ratios below 0.53 , in the manner already illustrated in figure 3 .

A No. 22 gage Chromel-Alumel thermocouple junction, filed to the form of a flat disk having a thickness equal to and a diameter twice that of a single wire, was mounted centrally at the downstream end of the cylindrical throat. Thermal electromotive forces in the tests of sonic pyrometers 2 and 3 were measured with a Brown Electronik potentiometer.

After calibration in the manner already described, the instrument was tested in the exhaust gas stream from a Jumo 004 combustor, using the equipment

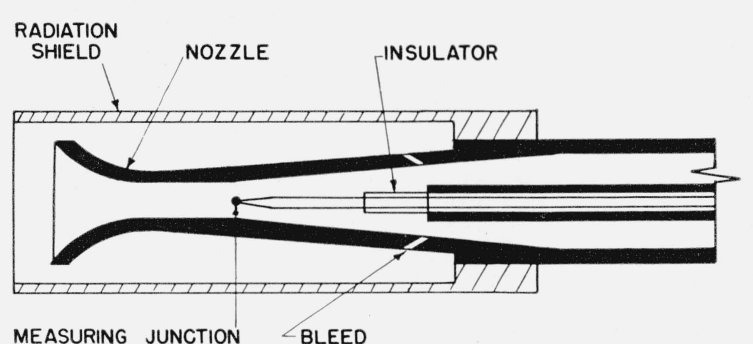

Figure 5. Diagram of sonic pyrometer 2. 
shown diagrammatically in figure 6. A shielded thermocouple, for which radiation corrections [5] were known accurately, and the sonic pyrometer, were inserted radially to the center of the 6 -in. test section. Gas velocities here did not exceed 300 $\mathrm{ft} / \mathrm{sec}$, so that the corrections for impact on the thermocouple were always less than $3 \mathrm{deg} F$.

Observations were made at gas temperatures from $400^{\circ}$ to $1,300^{\circ} \mathrm{F}$, in intervals of $100 \mathrm{deg} \mathrm{F}$. In most runs, the temperature of the walls was made equal to that of the gas, so that radiation could not affect either the shielded thermocouple or the sonic pyrometer. In order to determine the effects of radiation on the latter, other runs were made with the walls cooler than the gas by measured amounts.

All of the results with sonic pyrometer 2 are summarized in table 2. The calibration data, obtained with air at about room temperature, are given in the first horizontal line. For this unit, the calibration gives $\alpha=1.0205$ and $r=0.8795$. Starting at the left, columns in the table show in order the values of gas temperature indicated by the shielded thermocouple $\left(T_{1 i}\right)$, the corrections applied to the shielded couple for radiation $\left(\Delta T_{r}\right)$ and impact $\left(\Delta T_{v}\right)$, the corrected total temperature $\left(T_{1 i}=T_{1 i}+\Delta T_{r}+\Delta T_{v}\right)$ of the gas in the test system as determined with the radiation-shielded thermocouple, and the temperature indicated by the thermocouple of the sonic pyrometer $\left(T_{2 i}\right)$. Observed quantities not listed in table 2 are the pressure in the test section and the pyrometer discharge pressures.

The remaining columns of table 2 show the effects of various possible methods of computing $T_{2 t}$ from the observed values of $T_{2 i}$. In the column marked

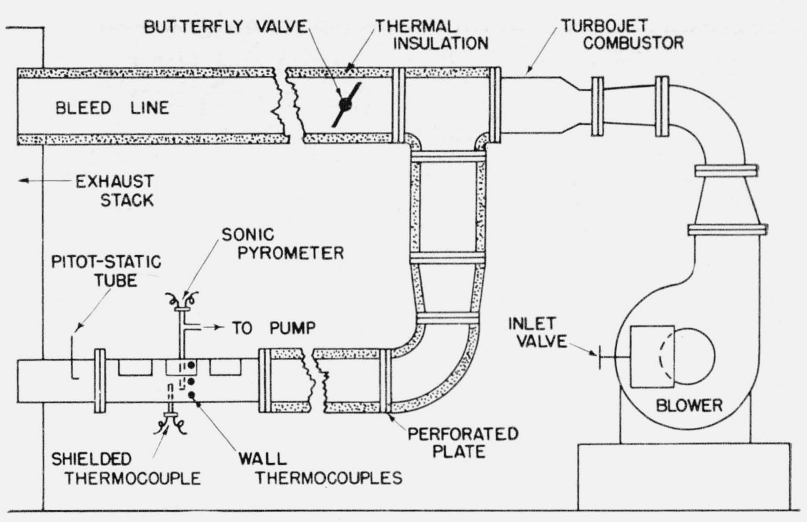

Figure 6. Schematic diagram of exhaust-gas system.

$\alpha$ (obs) the ratio $T_{2 t} / T_{2 i}$ is given for each run. While the maximum spread in the observed values of this ratio is only 0.4 percent, the ratio shows a definite decrease as the gas temperature increases. $A s$ is evident from the last two columns of table 2 , the ratio decreases linearly with temperature, in accordance with the empirical equation $T_{2 t} / T_{2 i}=$ $\alpha$ (smoothed $)=1.0225-38 \times 10^{-7} T_{1 i}$, in which $T_{1 i}$ is expressed in $\operatorname{deg} \mathrm{F}$.

If the value $\alpha=1.0205$, determined in the calibration with air at room temperature, is applied directly to the other runs, the temperatures listed in the column headed $T_{2 t}^{\prime}$ are obtained. The corresponding errors, $T_{2 t}-T_{2 t}^{\prime}$ include both the experimental errors and those introduced by neglecting changes in $\gamma$. Even so, the maximum error is less than 7 deg F, which is probably small enough for most purposes.

TABLE 2. Results with sonic pyrometer 2

\begin{tabular}{|c|c|c|c|c|c|c|c|c|c|c|c|c|c|c|c|}
\hline \multicolumn{6}{|c|}{ Silver-shielded thermocouple } & \multirow{2}{*}{$\begin{array}{c}\text { Sonic } \\
\text { pyrom- } \\
\text { eter, } T_{2 i}\end{array}$} & \multirow{2}{*}{$\begin{array}{c}\alpha(o b s) \\
=T_{2 t} l \\
T_{2 i}\end{array}$} & \multirow{2}{*}{$\begin{array}{c}T_{2 t}^{\prime}= \\
1.0205 T_{2 i}\end{array}$} & \multirow{2}{*}{$\begin{array}{c}T_{2 t}- \\
T_{2 t}^{\prime}\end{array}$} & \multirow[b]{2}{*}{$\gamma$} & \multirow{2}{*}{$\begin{array}{c}r \\
(\mathrm{eq} 7)\end{array}$} & \multirow{2}{*}{$\begin{array}{c}T_{2 t}^{\prime \prime}= \\
\frac{(\gamma+1) T_{2 i}}{2+0.8795(\gamma-1)}\end{array}$} & \multirow{2}{*}{$T_{2 t}-T_{2 t}^{\prime \prime}$} & \multirow{2}{*}{$\alpha(\mathrm{sm})^{\mathrm{a}}$} & \multirow{2}{*}{$\frac{\alpha(\mathrm{obs})-\alpha(\mathrm{sm})}{\alpha(\mathrm{obs})}$} \\
\hline$T$ & & $\Delta T_{r}$ & $\Delta T_{r}$ & $\begin{array}{l}T_{2 t}=T_{1 i}+ \\
\Delta T_{r}+\Delta T_{n}\end{array}$ & $\begin{array}{c}T_{1 i}- \\
T_{w}\end{array}$ & & & & & & & & & & \\
\hline \multicolumn{16}{|c|}{ Calibration run } \\
\hline $\begin{array}{l}{ }^{\circ} F \\
109.0\end{array}$ & $\begin{array}{l}{ }^{\circ} R \\
568.7\end{array}$ & $\begin{array}{c}{ }^{\circ} R \\
0\end{array}$ & $\begin{array}{c}{ }^{\circ} P \\
0\end{array}$ & $\begin{array}{l}{ }^{\circ} R \\
568.7\end{array}$ & $\stackrel{\circ}{\circ}$ & $\begin{array}{c}{ }^{\circ} R \\
557.3\end{array}$ & 1. 0205 & ${ }^{\circ} R$ & ${ }^{\circ} \underline{R}$ & 1. 3986 & 0.8795 & ${ }^{\circ} R$ & ${ }^{\circ} R$ & 1.0221 & $\begin{array}{c}\text { Percent } \\
-0.16\end{array}$ \\
\hline \multicolumn{16}{|c|}{ Runs without loss by radiation } \\
\hline $\begin{array}{r}400.0 \\
500.0 \\
590.0 \\
600.0 \\
697.5 \\
798.3 \\
900.0 \\
1000.0 \\
1090.0 \\
1100.0 \\
1200.0 \\
1300.0\end{array}$ & $\begin{array}{r}859.7 \\
959.7 \\
1049.7 \\
1059.7 \\
1157.2 \\
1258.0 \\
1359.7 \\
1459.7 \\
1549.7 \\
1559.7 \\
1659.7 \\
1759.7\end{array}$ & $\begin{array}{l}0 \\
0 \\
0 \\
0 \\
0 \\
0 \\
0 \\
0 \\
0 \\
0 \\
0 \\
0\end{array}$ & $\begin{array}{l}0.1 \\
0.7 \\
0.8 \\
1.0 \\
1.0 \\
1.3 \\
1.6 \\
1.8 \\
1.9 \\
1.9 \\
2.3 \\
2.6\end{array}$ & $\begin{array}{r}859.8 \\
960.4 \\
1050.5 \\
1060.7 \\
1058.2 \\
1259.3 \\
1361.3 \\
1461.5 \\
1551.6 \\
1561.6 \\
1662.0 \\
1762.3\end{array}$ & $\begin{array}{l}0 \\
0 \\
0 \\
0 \\
0 \\
0 \\
0 \\
0 \\
0 \\
0 \\
0 \\
0\end{array}$ & $\begin{array}{r}842.2 \\
941.7 \\
1030.2 \\
1039.9 \\
1135.5 \\
1234.6 \\
1333.9 \\
1432.4 \\
1523.6 \\
1531.8 \\
1632.7 \\
1733.5\end{array}$ & $\begin{array}{l}1.0209 \\
1.0199 \\
1.0197 \\
1.0200 \\
1.0200 \\
1.0200 \\
1.0205 \\
1.0203 \\
1.0184 \\
1.0194 \\
1.0179 \\
1.0166\end{array}$ & $\begin{array}{r}859.4 \\
961.0 \\
1051.3 \\
1061.2 \\
1158.6 \\
1259.9 \\
1361.2 \\
1461.8 \\
1554.8 \\
1563.2 \\
1666.2 \\
1769.0\end{array}$ & $\begin{aligned} & 0.4 \\
&-.6 \\
&-.8 \\
&-.5 \\
&-.6 \\
&-.6 \\
& .1 \\
&-.3 \\
&-3.2 \\
&-1.6 \\
&-4.2 \\
&-6.7\end{aligned}$ & $\begin{array}{l}1.384 \\
1.378 \\
1.371 \\
1.371 \\
1.363 \\
1.357 \\
1.350 \\
1.343 \\
1.337 \\
1.337 \\
1.331 \\
1.326\end{array}$ & $\begin{array}{r}0.873 \\
.877 \\
.877 \\
.875 \\
.872 \\
.871 \\
.865 \\
.864 \\
.875 \\
.868 \\
.876 \\
.883\end{array}$ & $\begin{array}{r}859.0 \\
959.6 \\
1049.8 \\
1059.7 \\
1157.1 \\
1257.6 \\
1358.3 \\
1458.1 \\
1550.5 \\
1558.9 \\
1661.1 \\
1763.3\end{array}$ & $\begin{array}{r}0.8 \\
.8 \\
.7 \\
1.0 \\
1.1 \\
1.7 \\
3.0 \\
3.4 \\
1.1 \\
2.7 \\
0.9 \\
-1.0\end{array}$ & $\begin{array}{l}1.0210 \\
1.0206 \\
1.0203 \\
1.0203 \\
1.0198 \\
1.0195 \\
1.0191 \\
1.0187 \\
1.0182 \\
1.0182 \\
1.0179 \\
1.0176\end{array}$ & $\begin{array}{r}-0.01 \\
-.07 \\
-.06 \\
-.03 \\
+.02 \\
+.05 \\
+.14 \\
+.16 \\
+.02 \\
+.12 \\
.00 \\
-.10\end{array}$ \\
\hline \multicolumn{16}{|c|}{ Runs to determine the effects of radiation } \\
\hline $\begin{array}{r}900.0 \\
1110.0 \\
1200.0 \\
1310.0\end{array}$ & $\begin{array}{l}1359.7 \\
1569.7 \\
1659.7 \\
1769.7\end{array}$ & $\begin{array}{l}1.8 \\
3.3 \\
4.5 \\
5.1\end{array}$ & $\begin{array}{l}1.8 \\
1.9 \\
2.1 \\
1.8\end{array}$ & $\begin{array}{l}1363.3 \\
1574.9 \\
1666.3 \\
1776.6\end{array}$ & $\begin{array}{l}378 \\
498 \\
559 \\
506\end{array}$ & $\begin{array}{l}1338.0 \\
1547.6 \\
1638.6 \\
1746.0\end{array}$ & $\begin{array}{l}1.0189 \\
1.0176 \\
1.0169 \\
1.0175\end{array}$ & $\begin{array}{l}1365.4 \\
1579.3 \\
1672.2 \\
1781.8\end{array}$ & $\begin{array}{l}-2.1 \\
-4.4 \\
-5.9 \\
-5.2\end{array}$ & $\begin{array}{l}1.350 \\
1.337 \\
1.331 \\
1.326 \\
\\
\text { Avg... }\end{array}$ & $\begin{array}{r}0.874 \\
.886 \\
.881 \\
.878 \\
0.875\end{array}$ & $\begin{array}{l}1362.4 \\
1575.0 \\
1667.4 \\
1776.0\end{array}$ & $\begin{array}{r}1.1 \\
-1.4 \\
-0.6 \\
.6\end{array}$ & $\begin{array}{l}1.0191 \\
1.0182 \\
1.0179 \\
1.0176\end{array}$ & $\begin{array}{r}-0.02 \\
-.06 \\
-.10 \\
-.01\end{array}$ \\
\hline
\end{tabular}

${ }^{\mathrm{a}} \alpha($ smoothed $)=1.0225-38 \times 10^{-7} T_{1 i}\left({ }^{\circ} \mathrm{F}\right)$. 


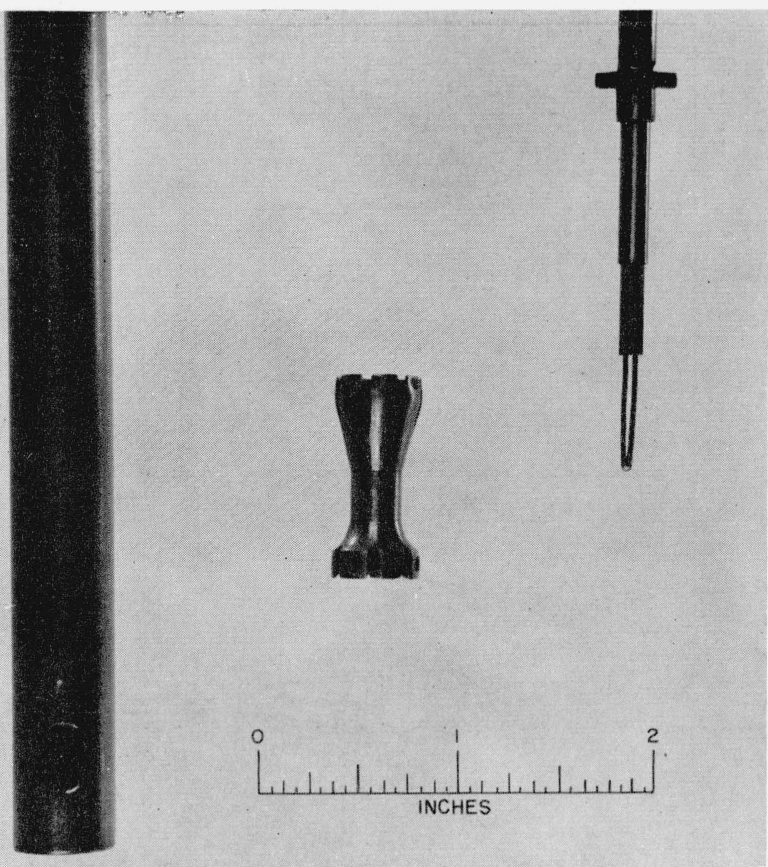

Figure 7. Dismantled sonic pyrometer 3.

A more accurate method of applying the calibration data is to calculate $r$ for the calibration run, and to use this value with the appropriate values of $\gamma$ in eq 7. This has been done in the column headed $T_{2 t}^{\prime \prime}$, and the maximum error $\left(T_{2 t}-T_{2 t}^{\prime \prime}\right)$ is found to be half as great as in the previous method of reduction. Furthermore $T_{2 t}-T_{2 t}^{\prime \prime}$ does not continue to increase with temperature. This merely shows that a small but definite improvement is made by taking the changes in $\gamma$ into account. It also illustrates, once again, that the $\gamma$ need not be known precisely, since a change from 1.400 to 1.326 alters the result by less than 6 deg $\mathrm{F}$.

Most of the differences, $T_{2 t}-T_{2 t}^{\prime \prime}$, are of the same sign, and in a direction indicating that the recovery factor determined in the calibration run was higher than that for the other runs. This can be examined in more detail by substituting the measured values of $T_{2 t}$ and $T_{2 i}$, along with appropriate values of $\gamma$, in eq 7 to calculate an individual value of $r$ for each run. As the tabulated results show, the maximum spread in $r$ is about 2.5 percent; the calibration $r$ is higher than most of the others and about 0.5 percent higher than the average. Possible explanations for this are discussed later in connection with the results obtained with pyrometer 3 .

If the effects of radiation and conduction on the performance of the sonic pyrometer are significant, these should be apparent in the last four horizontal lines of table 2 . In these runs, the walls were from 378 to 559 deg colder than the gas, yet the differences $T_{2 t}-T_{2 t}^{\prime}$ and $T_{2 t}-T_{2 t}^{\prime \prime}$ are no greater than they are at the same gas temperatures in the runs without heat losses. Hence it is concluded that the shielding features, plus the high mass flow rate over the measuring junction, combine to render the heat losses entirely negligible. It is obviously a great advantage

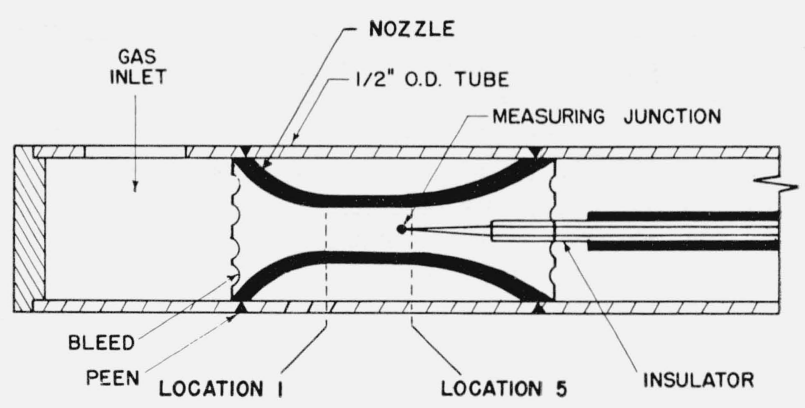

Figure 8. Diagram of sonic pyrometer 3.

of this type of instrument that this feature can be built in, so that no separate determination or evaluation of corrections is required.

On the basis of the highly encouraging results obtained with pyrometers 1 and 2 , it was considered desirable to design and evaluate a smaller unit, which might be installed in a restricted passage without blocking off the flow area unduly. To this end, unit No. 3 was built within a cylindrical tube having an external diameter of $1 / 2$ in. In addition to tests like those already described, the effects of the following features were investigated: axial location of the measuring junction; shape of the junction; the technique of calibration, with particular attention to the effect of moisture condensation if unheated and undried air is used; and the rate of response to sudden changes in temperature.

\subsection{Sonic Pyrometer 3}

In this unit, shown photographically in figure 7 and diagrammatically in figure 8 , the nozzle was made of 18-8 stainless steel and the outer tube of $1 / 2$-in. Inconel. The end of the latter was closed, and a $5 / 16$-in. diameter hole was drilled near the closed end of the tube for admission of gas.

The nozzle, having a cylindrical throat $0.157 \mathrm{in}$. in diameter and $1 / 4 \mathrm{in}$. long, was fitted snugly within the Inconel tube, except where notches were cut at either end to admit some gas to the intervening space. The tube was peened in to anchor the nozzle at both ends.

\section{a. Effects of Axial Location of the Junction}

During tests of this unit, various junctions of No. 22 gage Chromel and Alumel were mounted axially. Provision was made for locating the junction reproducibly at any one of the following positions:

\begin{tabular}{|c|c|}
\hline Location No. & $\begin{array}{c}\text { Distance } \\
\text { from up- } \\
\text { stream end } \\
\text { of cylindri- } \\
\text { cal throat }\end{array}$ \\
\cline { 2 - 2 } & Inches \\
& 0 \\
1 & $1 / 8$ \\
3 & $3 / 16$ \\
4 & $7 / 32$ \\
5 & $1 / 4$ \\
6 & $5 / 16$ \\
7 & $3 / 4$ \\
\hline
\end{tabular}


It was expected that sonic velocity would prevail at the downstream end of the cylindrical throat, but exact location of this plane in the hand-made nozzle is impossible. Hence tests were made with the measuring junction at locations only one thirtysecond in. apart in this region.

The calibration results obtained with air initially at about $100^{\circ} \mathrm{F}$. are presented in figure 9, in which the observed temperature differences $\left(T_{2 t}-T_{2 i}\right)$ are plotted against the suction, in inches of $\mathrm{Hg}$, applied at the outlet of the pyrometer, for each of the seven junction locations. The curves for locations 1 through 3 become horizontal after the critical pressure is reached. The plane of sonic velocity appears to be in the region between locations 3 and 5 , and probably between 3 and 4 , since the curve for location 4 continues to rise slightly as the suction is increased. The slope of the curves at higher suctions increases progressively at locations 5,6 , and 7 , indicating supersonic flow there.

The curves of figure 9 indicate that the gas velocity increases progressively from location 1 to location 7 . It is sonic somewhere in the one-sixteenth in. between locations 3 and 5. Only at this place do the equations for the sonic pyrometer apply exactly, because only here is the square of the gas velocity equal to $\gamma g R T_{s}$. However, this means merely that the junction should not be located downstream from position 5, and not that locating it farther upstream is seriously disadvantageous. As will be shown later, the instrument performs equally well with the junction at locations $2,3,4$, and 5 , and it is believed that location 1 would also have been found satisfactory if runs had been made with that configuration. This is so because the Mach number at any upstream station remains constant when the critical pressure ratio is maintained across the nozzle, and because the effect on recovery factor of variations in velocity at constant $M$ is insignificant.

Perhaps the most important conclusion to be drawn from figure 9 is that the junction should be kept at one and only one location during calibration and subsequent use. Full appreciation of the importance of junction location did not develop until after the tests of pyrometer 2 were completed. Therefore, some of the small variations in the ratio $T_{2 t} / T_{2 i}$ noted with that unit may have been due to insufficient care in bringing the junction always to the same axial location.

\section{b. Performance Tests}

Tests of sonic pyrometer 3 in exhaust gas were made in the same manner and with the same equipment used for unit 2. A series of runs was made with the measuring junction at locations $2,3,4$, and 5 . Again, most of the runs were made with the gas and the walls at the same temperature, and a limited number were made with colder walls to see whether the heat loss affected the instrument significantly. All of the results are presented in table 3 , which has the same general form as table 2 , and therefore need not be described in detail.

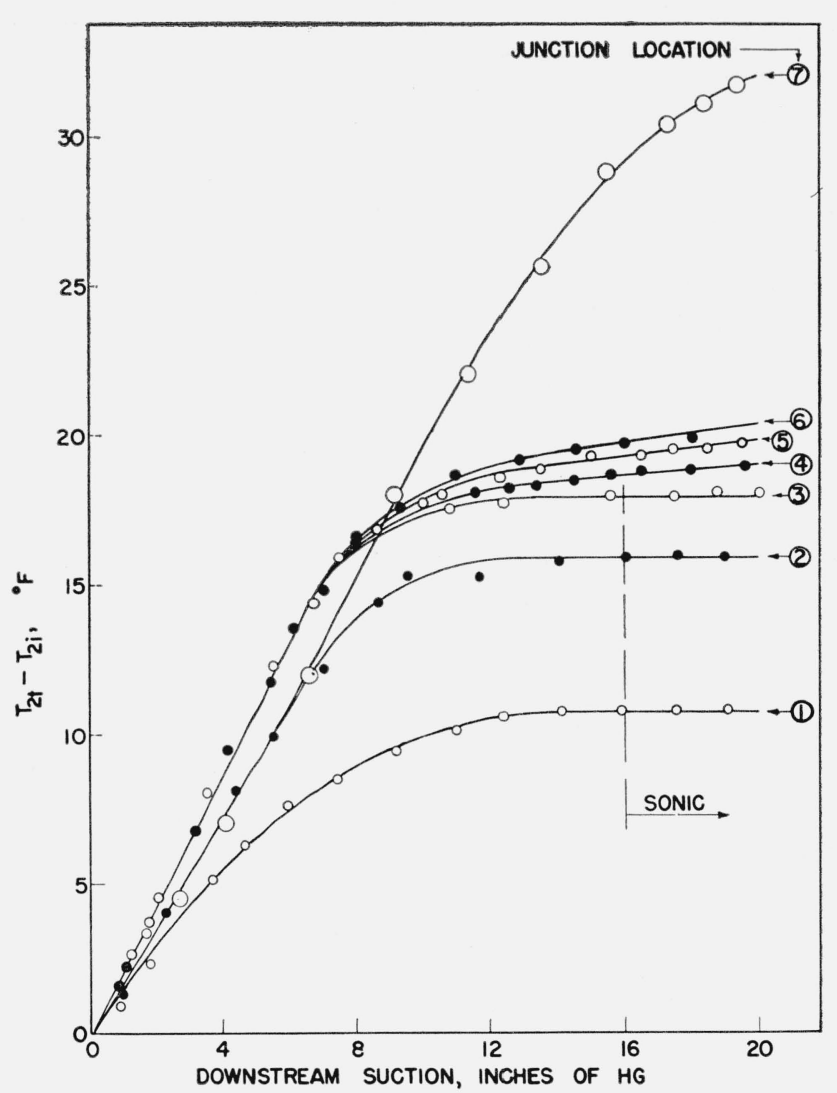

Figure 9. Effect of axial location of the measuring junction on the calibration of unit $3\left(T_{t}=100^{\circ} \mathrm{F}\right.$.).

In general, unit 3 showed the same characteristics as No. 2, namely that it was capable of measuring accurate values of the total temperature of streaming exhaust gas; that no corrections for radiation or conduction were required; and that the recovery factor determined with air at room temperature was slightly higher than the average of values determined at elevated temperatures.

In addition, the following characteristics are evident from the table. If an error of $15 \mathrm{deg} \mathrm{F}$ can be tolerated, it is necessary only to determine $\alpha$ with air at room temperature and to consider that $\alpha$ is constant. The total temperature is then the constant $\alpha$ times $T_{i}$, and $\gamma$ need not be known. If the recovery factor is calculated from the calibration and this value is held constant for all other runs, the error is reduced to less than $3 \mathrm{deg} F$ in the range up to $1,500^{\circ} \mathrm{F}$ when the appropriate values of $\gamma$ are used. These need not be known precisely.

The error can be reduced to less than $2 \operatorname{deg} \mathrm{F}$ if the instrument is calibrated over the range of temperatures in which it is to be used, and the resulting values of $r$ are used in conjunction with the proper values of $\gamma$. A separate accurate instrument is required for this kind of calibration, which is certainly not required for applications in engines where large temperature gradients are present normally. 
TABLE 3. Results with sonic pyrometer 3

\begin{tabular}{|c|c|c|c|c|c|c|c|c|c|c|c|c|c|c|c|c|}
\hline & \multicolumn{2}{|c|}{$T_{1 i}$} & $\Delta T_{\tau}$ & $\Delta T_{v}$ & $\begin{array}{l}T_{2 t}=T_{1 i}+ \\
\Delta T_{r}+\Delta T_{\mathrm{v}}\end{array}$ & $T_{1 i}-T_{w}$ & $T_{2 i}$ & $\begin{array}{l}a(o b s) \\
T_{2 t} / T_{2 i}\end{array}$ & $T_{2 t}^{\prime}$ & $T_{2 t}-T_{2 t}^{\prime}$ & $\gamma$ & $\left(\begin{array}{r}r, \\
7\end{array}\right)$ & $T_{2 t}^{\prime \prime}$ & $T_{2 t}-T_{2 t}^{\prime \prime}$ & $a(\mathrm{sm})$ & $\frac{a(\mathrm{obs})-a(\mathrm{sm})}{a(\mathrm{obs})}$ \\
\hline & \multicolumn{16}{|c|}{ Measuring Junction at Location 2} \\
\hline & $\begin{array}{l}{ }^{\circ} F \\
150\end{array}$ & $\begin{array}{l}\circ R \\
609.7\end{array}$ & ${ }_{0}^{\circ} R$ & $\begin{array}{l}{ }^{\circ} R \\
0.1\end{array}$ & $\begin{array}{l}{ }^{\circ} R \\
609.8\end{array}$ & ${ }^{\circ} R$ & $\begin{array}{l}\stackrel{\circ}{R} \\
590.8\end{array}$ & 1. 0322 & ${ }^{\circ} R$ & ${ }^{\circ} R$ & 1. 3978 & 0.812 & ${ }^{\circ} R$ & ${ }^{\circ} R$ & a 1.0342 & $\begin{array}{l}\text { Percent } \\
-0.22\end{array}$ \\
\hline Ralibration run & $\left(\begin{array}{r}540 \\
775 \\
895 \\
995 \\
1080 \\
1190 \\
1290\end{array}\right.$ & $\begin{array}{r}999.7 \\
1234.7 \\
1354.7 \\
1454.7 \\
1539.7 \\
1649.7 \\
1749.7\end{array}$ & $\begin{array}{l}0 \\
0 \\
0 \\
0 \\
0 \\
0 \\
0\end{array}$ & $\begin{array}{r}0.4 \\
.7 \\
.9 \\
1.1 \\
1.3 \\
1.3 \\
1.7\end{array}$ & $\begin{array}{l}1000.1 \\
1235.4 \\
1355.6 \\
1455.8 \\
1541.0 \\
1651.0 \\
1751.4\end{array}$ & $\begin{array}{l}0 \\
0 \\
0 \\
0 \\
0 \\
0 \\
0\end{array}$ & $\begin{array}{r}969.8 \\
1199.0 \\
1316.9 \\
1414.9 \\
1499.6 \\
1606.7 \\
1705.7\end{array}$ & $\begin{array}{l}\text { 1. } 0312 \\
\text { 1. } 0304 \\
\text { 1. } 0294 \\
\text { 1. } 0289 \\
\text { 1. } 0276 \\
\text { 1. } 0276 \\
1.0268\end{array}$ & $\begin{array}{l}1001.0 \\
1237.6 \\
1359.3 \\
1460.4 \\
1547.9 \\
1658.4 \\
1760.6\end{array}$ & $\begin{array}{r}0.1 \\
-2.2 \\
-3.7 \\
-4.6 \\
-6.9 \\
-7.4 \\
-9.2\end{array}$ & $\begin{array}{l}\text { 1. } 374 \\
\text { 1. } 356 \\
\text { 1. } 350 \\
\text { 1. } 344 \\
\text { 1. } 338 \\
\text { 1. } 332 \\
\text { 1. } 326\end{array}$ & $\begin{array}{l}0.808 \\
.805 \\
.805 \\
.807 \\
.814 \\
.811 \\
.814\end{array}$ & $\begin{array}{l}999.4 \\
1234.0 \\
1354.8 \\
1455.0 \\
1541.5 \\
1650.9 \\
1751.8\end{array}$ & $\begin{array}{r}0.7 \\
1.4 \\
0.8 \\
-.8 \\
-.5 \\
-.1 \\
-.4\end{array}$ & $\begin{array}{l}\text { 1. } 0317 \\
\text { 1. } 0302 \\
\text { 1. } 0294 \\
\text { 1. } 0287 \\
\text { 1. } 0232 \\
\text { 1. } 0275 \\
\text { 1. } 0268\end{array}$ & $\begin{array}{r}.05 \\
.02 \\
.00 \\
.02 \\
-.06 \\
.01 \\
.00\end{array}$ \\
\hline \multirow{3}{*}{$\begin{array}{l}\text { Run to determine the effects of } \\
\text { radiation. }\end{array}$} & \multirow[t]{2}{*}{1445} & \multirow[t]{2}{*}{ 1904. 7} & \multirow[t]{2}{*}{3.6} & \multirow[t]{2}{*}{1.8} & \multirow[t]{2}{*}{1910.1} & \multirow[t]{2}{*}{195} & \multirow[t]{2}{*}{1862.3} & \multirow[t]{2}{*}{1.0257} & \multirow[t]{2}{*}{1922.3} & \multirow[t]{2}{*}{-12.2} & \multirow{2}{*}{$\begin{array}{l}1.318 \\
\quad \mathrm{Avg}_{--}\end{array}$} & .817 & \multirow[t]{2}{*}{1911.6} & \multirow[t]{2}{*}{-1.5} & \multirow[t]{2}{*}{ 1. 0258} & \multirow[t]{2}{*}{-.01} \\
\hline & & & & & & & & & & & & 0.811 & & & & \\
\hline & \multicolumn{16}{|c|}{ Measuring Junction at Location 3} \\
\hline Calibration run & \multirow{3}{*}{$\begin{array}{r}110 \\
\left\{\begin{array}{r}550 \\
700 \\
790 \\
890 \\
990 \\
1085 \\
1195 \\
\{1375 \\
1435\end{array}\right.\end{array}$} & 569.7 & 0 & 0.1 & 569.8 & 0 & 551.3 & 1. 0336 & $10326 T$ & -....- & 1. 3986 & 0.804 & $x=0.84$ & & b 1.0366 & -0.30 \\
\hline $\begin{array}{l}\text { Runs to determine effects of } \\
\text { radiation }\end{array}$ & & $\begin{array}{l}1009.7 \\
1159.7 \\
1249.7 \\
1349.7 \\
1449.7 \\
1544.7 \\
1654.7 \\
1834.7 \\
1894.7\end{array}$ & $\begin{array}{l}0 \\
0 \\
0 \\
0 \\
0 \\
0 \\
0 \\
3.5 \\
4.0\end{array}$ & $\begin{array}{r}0.4 \\
.7 \\
.8 \\
.9 \\
1.1 \\
1.2 \\
1.4 \\
1.8 \\
1.8\end{array}$ & $\begin{array}{l}1010.1 \\
1160.4 \\
1250.5 \\
1350.6 \\
1450.8 \\
1545.9 \\
1656.1 \\
1840.0 \\
1900.5\end{array}$ & $\begin{array}{r}9 \\
0 \\
0 \\
0 \\
0 \\
0 \\
0 \\
200 \\
235\end{array}$ & $\begin{array}{r}977.8 \\
1123.8 \\
1211.4 \\
1309.6 \\
1407.1 \\
1501.0 \\
1609.2 \\
1789.0 \\
1849.2\end{array}$ & $\begin{array}{l}\text { 1. } 0330 \\
\text { 1. } 0326 \\
\text { 1. } 0323 \\
\text { 1. } 0313 \\
\text { 1. } 0310 \\
\text { 1. } 0299 \\
\text { 1. } 0291 \\
\text { 1. } 0225 \\
\text { 1. } 0277\end{array}$ & $\begin{array}{r}1010.6 \\
1161.6 \\
1252.1 \\
1353.6 \\
1454.4 \\
1551.4 \\
1663.3 \\
1849.1 \\
1911.3\end{array}$ & $\begin{array}{l}-0.5 \\
-1.2 \\
-1.6 \\
-3.0 \\
-3.6 \\
-5.5 \\
-7.2 \\
-9.1 \\
-10.8\end{array}$ & $\begin{array}{l}\text { 1. } 374 \\
\text { 1. } 363 \\
\text { 1. } 357 \\
\text { 1. } 350 \\
\text { 1. } 344 \\
\text { 1. } 338 \\
\text { 1. } 332 \\
\text { 1. } 321 \\
\text { 1. } 318\end{array}$ & $\begin{array}{l}.797 \\
.794 \\
.793 \\
.796 \\
.795 \\
.799 \\
.801 \\
.800 \\
.804\end{array}$ & $\begin{array}{l}1008.9 \\
1158.6 \\
1248.4 \\
1348.9 \\
1448.7 \\
1544.7 \\
1655.3 \\
1838.7 \\
1900.2\end{array}$ & $\begin{array}{l}1.2 \\
1.8 \\
2.1 \\
1.7 \\
2.1 \\
1.1 \\
0.8 \\
1.3 \\
0.3\end{array}$ & $\begin{array}{l}\text { 1. } 0337 \\
\text { 1. } 0327 \\
\text { 1. } 0322 \\
\text { 1. } 0315 \\
\text { 1. } 0309 \\
\text { 1. } 0303 \\
\text { 1. } 0295 \\
\text { 1. } 0284 \\
\text { 1. } 0280\end{array}$ & $\begin{array}{r}-.07 \\
-.01 \\
-.01 \\
-.02 \\
-.01 \\
-.04 \\
-.04 \\
-.01 \\
-.03\end{array}$ \\
\hline & & & & & & & & & & & Avg & 0.798 & & & & \\
\hline & & & & & & & & Measuri & Junction & it Location & & & & & & \\
\hline Calibration run.... & 110 & 569.7 & 0 & 0.1 & 569.8 & 0 & 550.6 & 1. 0349 & 1. $0349 \mathrm{~T}_{\mathrm{i}}$ & -....- & 1. 3986 & 0.797 & & -...-- & • 1.0380 & -0.31 \\
\hline & $\begin{array}{l}490 \\
605\end{array}$ & $\begin{array}{r}979.7 \\
1064.7\end{array}$ & $\begin{array}{l}0 \\
0\end{array}$ & .4 & $\begin{array}{r}950.1 \\
1065.3\end{array}$ & $\begin{array}{l}0 \\
0\end{array}$ & $\begin{array}{r}918.3 \\
1030.3\end{array}$ & $\begin{array}{l}\text { 1. } 0346 \\
\text { 1. } 0340\end{array}$ & $\begin{array}{r}950.3 \\
1066.2\end{array}$ & $\begin{array}{r}-0.2 \\
-.8\end{array}$ & $\begin{array}{l}1.378 \\
1.370\end{array}$ & $\begin{array}{r}790 \\
.789\end{array}$ & $\begin{array}{r}948.9 \\
1064.0\end{array}$ & $\begin{array}{l}1.2 \\
1.3\end{array}$ & $\begin{array}{l}\text { 1. } 0354 \\
\text { 1. } 0346\end{array}$ & $\begin{array}{l}-.08 \\
-.06\end{array}$ \\
\hline & 705 & 1164.7 & 0 & .7 & 1165.4 & 0 & 1127.2 & 1. 0339 & 1166.5 & -1.1 & 1.363 & .786 & 1163.5 & 1.9 & 1. 0339 & .00 \\
\hline Runs without loss by radiation. & 790 & 1249.7 & 0 & .8 & 1250.5 & 0 & 1210.1 & 1. 0334 & 1252.3 & -1.8 & 1. 357 & .787 & 1248.5 & 2.0 & 1.0333 & .01 \\
\hline & $\begin{array}{l}880 \\
985\end{array}$ & $\begin{array}{l}1339.7 \\
1444.7\end{array}$ & $\begin{array}{l}0 \\
0 \\
0\end{array}$ & .9 & $\begin{array}{l}1340.6 \\
1445.8\end{array}$ & 0 & $\begin{array}{l}1298.2 \\
1400\end{array}$ & 1. 0327 & 1343.5 & $\begin{array}{l}-2.9 \\
-3.8\end{array}$ & 1. 350 & .787 & 1338.7 & 1.9 & 1. 0326 & .01 \\
\hline & 1090 & 1549.7 & 0 & 1.3 & 1551.0 & 0 & 1503.8 & 1. 0314 & $\begin{array}{l}1449.6 \\
1556.3\end{array}$ & $\begin{array}{l}-5.8 \\
-5.3\end{array}$ & $\begin{array}{l}1.344 \\
1.338\end{array}$ & .789 & $\begin{array}{l}1443.7 \\
1549.2\end{array}$ & $\begin{array}{l}2.1 \\
1.8\end{array}$ & $\begin{array}{l}\text { 1. } 0319 \\
1.0312\end{array}$ & .02 \\
\hline & 1185 & 1644.7 & 0 & 1.3 & 1646.0 & 0 & 1597.4 & 1. 0304 & 1653.1 & -7.1 & 1. 332 & .793 & 1644.9 & 1.1 & 1. 0305 & -.01 \\
\hline & 1420 & 1879.7 & 3.5 & 1.8 & 1885.0 & 200 & 1832.4 & 1. 0287 & 1896.4 & -11.4 & 1. 319 & .797 & 1885. 0 & 0.0 & 1.0289 & -.02 \\
\hline radiation & 1435 & $\begin{array}{l}1894.7 \\
1059\end{array}$ & 3. 0 & 1.8 & 1899.5 & 165 & 1847.5 & 1. 0281 & 1912. 0 & -12.5 & 1. 318 & .801 & 1900.4 & -.9 & 1. 0288 & -.07 \\
\hline & & & & & & & & & & & & & & & & \\
\hline & & & & & & & & & & & Avg. & 0.792 & & & & \\
\hline & & & & & & & & Measuri & Junction & it Location & & & & & & \\
\hline Calibration run... & 100 & 559.7 & 0 & 0.1 & 559.8 & 0 & 539.5 & 1. 0376 & & ....... & 1. 3988 & 0.782 & & -....... & d 1.0395 & -0.19 \\
\hline & & 989.7 & 0 & .4 & 990.1 & 0 & 954.7 & 1. 0371 & $\begin{array}{c}1.0376 T_{1 i} \\
990.6\end{array}$ & & 1. 376 & .774 & $\begin{array}{l}r=0.782 \\
988.8\end{array}$ & 1.3 & 1. 0370 & \\
\hline & 575 & 1034.7 & 0 & .4 & 1035.1 & 0 & 999.0 & 1. 0361 & 1036. 6 & -1.5 & 1. 372 & .778 & 1034.4 & 0.7 & 1. 0367 & -.06 \\
\hline & 715 & 1174.7 & 0 & .6 & 1175.3 & 0 & 1134.6 & 1. 0359 & 1177.3 & -2.0 & 1. 362 & .774 & 1173.8 & 1.5 & 1. 0359 & .00 \\
\hline & 805 & 1264.7 & 0 & .8 & 1265.5 & 0 & 1222.4 & 1. 0352 & & -2.9 & 1. 356 & .775 & 1264.0 & 1.5 & 1. 0354 & -.02 \\
\hline Runs without loss by radiation & 895 & 1354.7 & 0 & .9 & 1355.6 & 0 & 1309.5 & 1. 0352 & 1358. 7 & -3.1 & 1. 350 & .772 & 1353.4 & 2. 2 & 1. 0348 & .04 \\
\hline & 1000 & 1459.7 & 0 & $\begin{array}{l}1.1 \\
1.2\end{array}$ & 1460.8 & 0 & 1412. 9 & 1. 0339 & 1466.0 & -5.2 & 1. 343 & .776 & 1459.5 & 1.3 & 1. 0342 & -.03 \\
\hline & 1085 & 1544.7 & 0 & $\begin{array}{l}1.3 \\
1.3\end{array}$ & 1546. 0 & 0 & $\begin{array}{l}1495.8 \\
1593.5\end{array}$ & $\begin{array}{l}1.0336 \\
1.0320\end{array}$ & 1552.0 & -6.0 & 1.338 & .775 & 1544.5 & 1.5 & 1. 0337 & -.01 \\
\hline & $\begin{array}{l}1185 \\
1280\end{array}$ & $\begin{array}{l}1644.7 \\
1739.7\end{array}$ & $\begin{array}{l}0 \\
0\end{array}$ & $\begin{array}{l}1.3 \\
1.5\end{array}$ & $\begin{array}{l}1646.0 \\
1741_{2}\end{array}$ & ${ }_{0}^{0}$ & $\begin{array}{l}1593.5 \\
1686.4\end{array}$ & $\begin{array}{l}1.0329 \\
10325\end{array}$ & $\begin{array}{l}1653.4 \\
179.8\end{array}$ & $\begin{array}{l}-7.4 \\
-8.6\end{array}$ & $\begin{array}{l}1.331 \\
1.326\end{array}$ & .776 & 1644.4 & 1.6 & $\begin{array}{l}1.0331 \\
1.0325\end{array}$ & -.02 \\
\hline & 1320 & 1779.7 & 2.6 & 1.6 & $\begin{array}{l}1741.2 \\
1783.9\end{array}$ & 170 & $\begin{array}{l}1686.4 \\
1730.2\end{array}$ & $\begin{array}{l}\text { 1. } 0325 \\
1.0310\end{array}$ & $\begin{array}{l}1749.8 \\
1795.2\end{array}$ & $\begin{array}{r}-8.6 \\
-11.3\end{array}$ & $\begin{array}{l}1.326 \\
1.324\end{array}$ & .784 & $\begin{array}{l}1739.5 \\
1784.4\end{array} \quad-10$ & -0.5 & $\begin{array}{l}\text { 1. } 0325 \\
\text { 1. } 0323\end{array}$ & $\begin{array}{r}.00 \\
-.13\end{array}$ \\
\hline Runs to determine effects of & 1465 & 1924.7 & 3. 2 & 1.9 & 1929.8 & 165 & 1871.4 & 1. 0312 & 1941.8 & -12.0 & 1. 317 & .779 & 1928.9 & .9 & 1. 0315 & -.03 \\
\hline radiation ....................... & 1483 & 1942.7 & 2.6 & 1.9 & 1947.2 & 143 & 1889.6 & 1. 0305 & 1960.6 & -13.4 & 1.316 & .783 & 1947.5 & -.3 & 1. 0314 & -.09 \\
\hline & & & & & & & & & & & Avg.. & 0.777 & & & & \\
\hline
\end{tabular}

a $\alpha$ (smoothed $)=1.0352-65 \times 10^{-7} T_{1 i}\left({ }^{\circ} \mathrm{F}\right)$. 


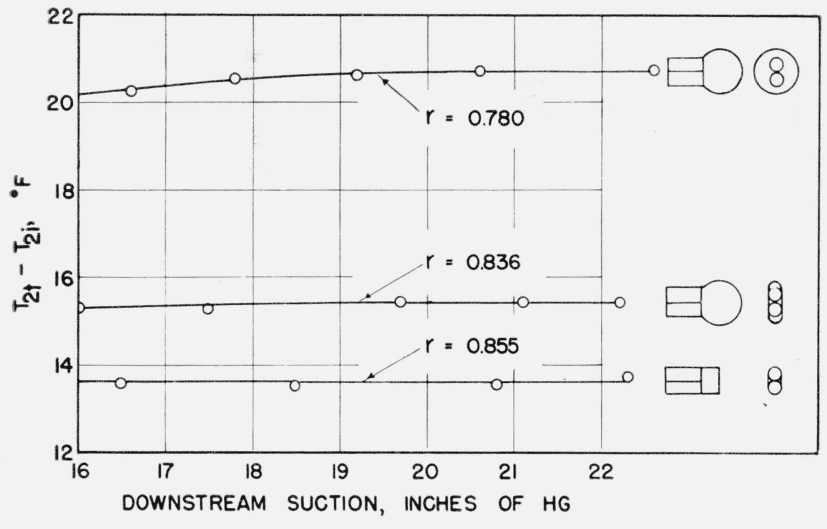

Figure 10. Effects of the shape of the measuring junction.

\section{c. Effects of the Shape of the Junction}

The measuring junction used in obtaining the results shown in table 3 was approximately spherical. This accounts for the fact that its recovery factor is lower than that of the flat junction used in unit 2 . To further check on the effects of junction shape, unit 3 was calibrated with a junction in the form of a spherical bead, with one having the bead filed to a disk with thickness equal to the wire diameter, and with a third dressed until the upstream end had the area of the two thermocouple wires plus the two small welding fillets. These junction shapes can be visualized from the diagrams in figure 10, which also shows the results obtained with each of these junctions at location 4 . The recovery factor of the junctions increase in the order in which they have been described, so that the junction with most of the bead filed away is best for use in a sonic pyrometer.

\section{d. Effect of Moisture Condensation on Recovery Factor}

As stated previously, each value of recovery factor determined with air at room temperature was slightly higher than the average of values determined at elevated temperatures. It was thought that this might be caused by condensation of water vapor during expansion through the nozzle, which is accompanied by a decrease of about $100 \mathrm{deg} \mathrm{F}$ in the static temperature of the gas. To check this hypothesis, a calibration system was devised whereby the temperature of the calibration air could be increased at will from ambient to about the boiling point of water. Depending upon the relative humidity of the ambient air, somewhere in this range the temperature becomes high enough that the dew point will not be reached in the throat of the nozzle.

The results of this calibration, made with a junction of minimum size at location 4 in pyrometer 3 , are shown by the open circles in figure 11, in terms of recovery factor as a function of upstream temperature. The filled circles were obtained in a series of runs to be described later. The observed values of $r$ decrease as the temperature of the inlet air rises and seem to approach a constant minimum value Effects of moisture condensation are believed re-

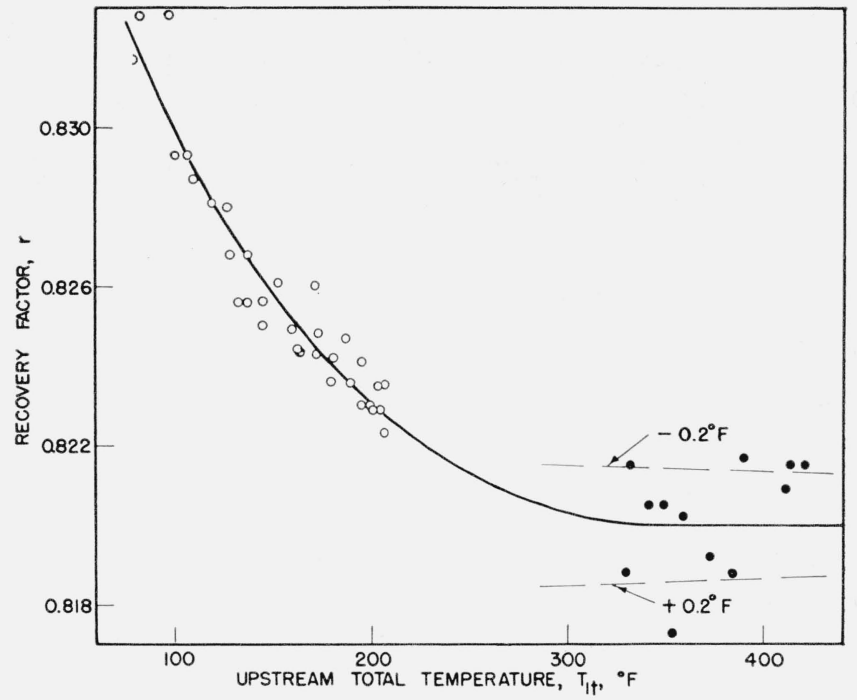

FiguRE 11. Variation in recovery factor at low inlet temperatures, showing the effect of moisture condensation in the nozzle.

sponsible for the initial marked decrease in $r$. It is recognized also that changes in the axial location of the junction may result from differential expansion, though these are surely small because Chromel, Alumel, and Inconel have nearly identical coefficients of thermal expansion.

Actually the curve of figure 11 is of more importance in showing how small, rather than how large, are the changes in $r$. The converging dashed lines at the right of the figure show the variation in $r$, which would produce an error of $\pm 0.2 \mathrm{deg}$ F. As another example, at $400^{\circ} \mathrm{F}$ a change in $r$ over the entire range covered by the curve, that is from 0.820 to 0.833 , would introduce an error of only $1.9 \mathrm{deg} \mathrm{F}$.

\section{e. Effect of Free-Stream Velocity}

Although the free-stream velocity was not expected to affect the performance of a sonic pyrometer, this was checked in simple tests with available equipment. Compressed air, heated in an exchanger, was passed through a 4 -in. tube and discharged through a 2 -in. nozzle into the atmosphere. A total-temperature probe was installed at the center of the 4-in. tube just upstream of the nozzle. The $5 / 16$-in. gas inlet to pyrometer 3 was placed in the axis of the jet, about 2 in. from the nozzle. As in the tests just described, the measuring junction had a minimum area and was at location 4 . The total temperatue of the air was varied from about $330^{\circ}$ to $420^{\circ} \mathrm{F}$. and its velocity at the pyrometer from about 260 to $1,260 \mathrm{ft} / \mathrm{sec}$. The results are presented in table 4 .

The average value of the recovery factor over the range of these tests was 0.820 , as can be seen from the filled circles in figure 11, as well as from table 4 . In the next to the last column of this table, it can be seen that the gas temperatures observed with the total temperature probe and those calculated from the sonic pyrometer by eq 7 with $r=0.820$ are practically identical. This agreement at all velocities 
through sonic is proof that the performance of the sonic pyrometer is completely independent of the free-stream velocity.

\section{f. Rate of Response}

When a temperature-sensing instrument immersed in the gas stream of an engine is to be used for control purposes, its rate of response to sudden changes in temperature is of greater importance than its absolute accuracy. It was therefore of interest to determine the characteristic time $(\tau)$ of sonic pyrometer 3. Using a method that has been described elsewhere [6], this pyrometer, with a spherical measuring junction at location 5, was tound to have a characteristic time of $0.65 \mathrm{sec}$ at several free-stream mass flow rates $(G)$ between 3 and $5 \mathrm{lb} / \mathrm{sec} \mathrm{ft}^{2}$. Under the conditions of these measurements, the mass flow rate in the throat of the sonic nozzle was approximately $30 \mathrm{lb} / \mathrm{sec} \mathrm{ft}^{2}$. From previous tests, the bare junction alone in the free stream was known to have a characteristic time ot $1.1 \mathrm{sec}$ at a mass flow rate of $3 \mathrm{lb} / \mathrm{sec} \mathrm{ft}^{2}$. Thus the sonic pyrometer tested has a characteristic time approximately six-tenths as great as that which its measuring junction alone would have in the same free stream. This advantage is greatest at low stream velocities, and decreases to zero when the free-stream. velocity is sonic, as may be seen in figure 12. In this example, it is assumed that a given thermocouple junction has a $\tau$ of 1.0 sec at a mass flow rate of $4 \mathrm{lb} / \mathrm{sec} \mathrm{ft}^{2}$; that $\tau$ is inversely proportional to $G^{1 / 2}$ that the volume of gas within the pyrometer and upstream. of the junction is zero; and that the total temperature and static pressure of the free stream are held constant at $2,000^{\circ} \mathrm{R}$ and $1 \mathrm{~atm}$, respectively, as the stream. velocity is varied.

The observed advantage of the sonic pyrometer as to the rate of response is not as great as might be expected from a consideration of the mass flow rates alone. On this basis, the $\tau$ of the junction used during the determinations of characteristic time should be about 0.4 sec at a mass flow rate of 30 $\mathrm{lb} / \mathrm{sec} \mathrm{ft}^{2}$. Since the $\tau$ of the complete instrument was $0.65 \mathrm{sec}$, the difference must be due to the time required for the displacement of gas already within the pyrometer. It was therefore of interest to

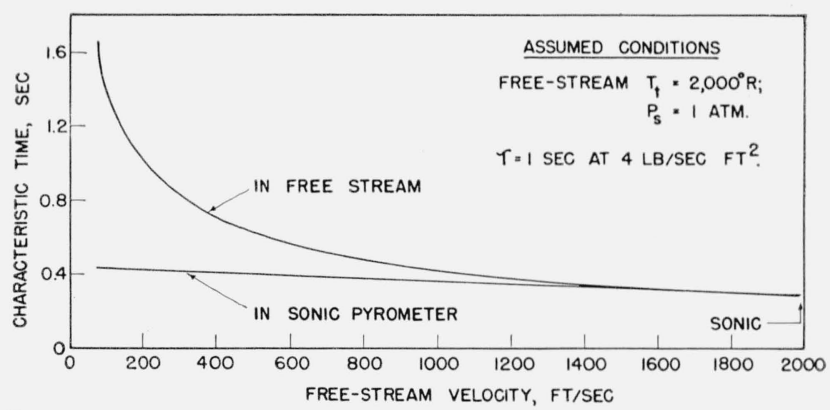

Figure 12. Comparison of the characteristic times of a No. 22 gage bare junction in the free stream and within a sonic pyrometer in the same stream.

determine whether the $\tau$ of the instrument could be decreased materially by removing the stagnation chamber, that is, that portion of the Inconel tube that projected upstream from the nozzle.

\section{g. Effects of Removing the Stagnation Chamber}

Actually this modification reduced the characteristic time of the pyrometer by only about 10 percent. In addition, the unit became sensitive to the freestream. velocity, as can be seen in figure 13 . Here the apparent recovery factor of the modified unit, plotted in terms of stream velocity, is seen to decrease to about 0.38 at sonic velocity. This cannot be a real recovery factor, and must reflect the effect of velocity. It is concluded that the stagnation chamber performs an essential function in a practical instrument, and cannot be dispensed with for the sake of a slight decrease in characteristic time.

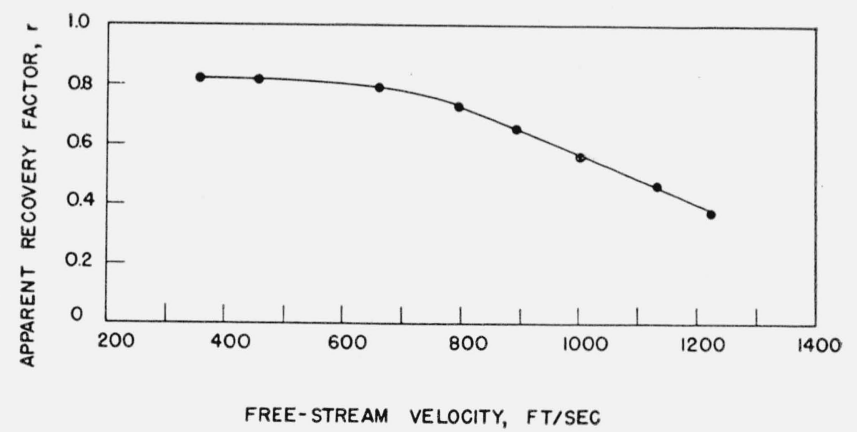

FIGURE 13. Effect of removing the stagnation chamber of sonic pyrometer 3 .

TABLE 4. Effect of free-stream velocity on sonic pyrometer 3

\begin{tabular}{|c|c|c|c|c|c|c|c|c|}
\hline \multicolumn{2}{|c|}{$T_{1 t}=T_{2 t}$} & $\begin{array}{c}T_{2 i} \\
{ }^{\circ} R \\
789.0\end{array}$ & $\begin{array}{c}\alpha=T_{2 t} / T_{2 i} \\
1.0308\end{array}$ & $\gamma$ & $r$ & $\begin{array}{c}T_{2 t}^{\prime \prime} \text {, eq } 7, \\
r=0.820 \\
{ }^{\circ} R\end{array}$ & $\begin{array}{c}T_{2 t}-T_{2 t}^{\prime \prime} \\
{ }^{\circ} R \\
0.4\end{array}$ & $\begin{array}{c}\text { Velocity, } V \\
f t / s e c \\
260\end{array}$ \\
\hline $\begin{array}{l}{ }^{\circ} F \\
353.6 \\
385.0 \\
414.0 \\
420.7 \\
412.5 \\
390.7 \\
373.5 \\
360.3 \\
349.8 \\
343.2 \\
336.7 \\
331.0\end{array}$ & $\begin{array}{c}{ }^{\circ} R \\
813.3 \\
844.7 \\
873.7 \\
880.4 \\
872.2 \\
850.4 \\
833.2 \\
820.0 \\
809.5 \\
802.9 \\
796.4 \\
790.7\end{array}$ & $\begin{array}{l}{ }^{\circ} R \\
789.0 \\
819.8 \\
848.4 \\
854.9 \\
846.9 \\
825.7 \\
808.6 \\
795.9 \\
785.7 \\
779.3 \\
772.9 \\
767.2\end{array}$ & $\begin{array}{l}1.0308 \\
1.0304 \\
1.0298 \\
1.0298 \\
1.0299 \\
1.0299 \\
1.0304 \\
1.0303 \\
1.0303 \\
1.0303 \\
1.0304 \\
1.0306\end{array}$ & $\begin{array}{l}1.391 \\
1.389 \\
1.387 \\
1.387 \\
1.387 \\
1.389 \\
1.390 \\
1.391 \\
1.392 \\
1.392 \\
1.392 \\
1.392\end{array}$ & $\begin{array}{l}0.817 \\
.819 \\
.822 \\
.822 \\
.821 \\
.822 \\
.819 \\
.820 \\
.820 \\
.820 \\
.822 \\
.819 \\
\end{array}$ & $\begin{array}{c}{ }^{\circ} R \\
812.9 \\
844.5 \\
873.9 \\
880.6 \\
872.4 \\
850.6 \\
833.1 \\
820.0 \\
809.6 \\
803.0 \\
796.4 \\
790.5\end{array}$ & $\begin{array}{r}{ }^{\circ} R \\
0.4 \\
.2 \\
-.2 \\
-.2 \\
-.2 \\
-.2 \\
.1 \\
.0 \\
-.1 \\
-.1 \\
.0 \\
.2\end{array}$ & $\begin{array}{c}f t / s e c \\
260 \\
352 \\
452 \\
646 \\
848 \\
982 \\
1,089 \\
1,160 \\
1,223 \\
1,257 \\
\text { Supersonic } \\
\text { Do. }\end{array}$ \\
\hline & & & & Avg.... & 0.820 & & & \\
\hline
\end{tabular}




\section{Conclusion}

The so-called sonic pyrometer is an instrument in which a thermocouple junction is located in the axis of a critical-flow nozzle, at or near the plane of sonic flow. Adequate shielding from radiation is simple to accomplish, and the entire instrument can be built within a tube $1 / 2$ in. in outside diameter. As compared with a bare thermocouple in a free stream, the sonic pyrometer has the following advantages:

(a) Errors due to heat loss by radiation can be made negligible under normal engine operating conditions.

(b) It measures free-stream total temperatures, regardless of free-stream velocity, so that the latter need not be known.

(c) It is relatively simple to calibrate, and accurate to within about $3 \mathrm{deg} \mathrm{F}$ up to $1,500^{\circ} \mathrm{F}$ when approximate values of $\gamma$ are known and used in calculating total temperatures from indicated values.

(d) Calibration with air at room temperature, and the application of a constant correction factor so determined, gives turbine exhaust gas temperatures that are accurate to within about $15 \mathrm{deg} F$ up to $1,500^{\circ} \mathrm{F}$, without any knowledge of or corrections for the $\gamma$ of the gas.

(e) Because the velocity over the measuring junction is always sonic, the mass flow rate past the junction is greater than that of the free stream, until the latter also becomes sonic. Hence a given junction in a sonic pyrometer responds more rapidly to sudden changes in temperature than would the same junction in the free stream. This advantage becomes greater as the free-stream velocity decreases.

As compared with a bare thermocouple in the free stream, the sonic pyrometer has the following disadvantages:

(a) It is more complicated and expensive to build.

(b) A pump is required whenever the ratio of the pressure in the throat of the nozzle to the free-stream total pressure is greater than 0.53 , and in this case the sonic pvrometer is not convenient for flight tests.

(c) The bare thermocouple can be made smaller.

The following precautions in the design and use of sonic pyrometers are suggested by the present results:

(a) The measuring junction should consist of a bead of the smallest practicable dimensions. Suca a junction has a higher recovery factor than any larger beads that were tried; one which, in fact, is within a few percent of the theoretical value for a flat plate.

(b) The throat of the nozzle should be large enough, and the thermocouple junction small enough, that the blocked area is $n+$ excessive. In the present unit No. 3, the smallest and the largest junctions blocked about 6 and 11 percent of the area of the throat, respectively. Both configurations of the device functioned in accordance with theory. (c) The measuring junction should be located as near the plane of sonic flow as is practicable. Location somewhat upstream of this plane is satisfactory, but the junction should never be located downstream, in a region where the flow may be supersonic.

(d) The measuring junction should be fixed axially so that its location cannot change during calibration and subsequent use.

(e) When rapid response to sudden changes in temperature is desired, the volume within the pyrometer and upstream from the measuring junction should be kept to a practicable minimum.

(f) The resistance to flow between the discharge of the nozzle and the external port of the unit should be kept low, in order that sonic velocity may be attained in the nozzle with a minimum of pumping effort.

(g) Use of a convergent-divergent nozzle is also advantageous in reducing the pumping effort.

(h) The sonic pyrometer should never be used for measuring gas temperature unless it is known that critical flow prevails in the nozzle.

(i) Where high accuracy is required, it is recommended that the sonic pyrometer be calibrated with air initially at or above $200^{\circ} \mathrm{F}$. In this way errors due to condensation of water vapor during the expansion through the nozzle are avoided.

Characteristics of the sonic pyrometer that have not been investigated include the following:

(a) Its ability to withstand mechanical vibration.

(b) The minimum practicable size.

(c) The maximum permissible throat area that may be blocked by the measuring junction.

(d) The effect of lateral displacement of the measuring junction from the axis of the nozzle.

(e) The effect of using dry air for calibration.

Each of these items can be treated more logically if and when practical needs arise that cannot be met by the instruments and test methods described above.

\section{References}

[1 S. Allen and J. R. Hamm, A pyrometer for measuring total temperature in low density gas streams, Trans. ASME 72, 851 (1950).

[2] J. H. Keenan and J. Kaye, Thermodynamic properties of air (John Wiley and Son, Inc., New York, N. Y., 1945).

[3] E. Pohlhausen, Heat exchange between solid bodies and liquids of low viscosity and low thermal conductivity, Z. angew. Math. u. Mech. 1, 115 (1921).

[4] H. W. Emmons and J. G. Brainerd, Temperature effects in a laminar compressible fluid boundary layer along a flat plate, Trans. ASME 63, A-105 (1941).

[5] A. I. Dahl and E. F. Fiock, Shielded thermocouples for gas turbines, Trans. ASME $\boldsymbol{7 1}, 153$ (1949).

[6] A. I. Dahl and E. F. Fiock, Response characteristics of temperature-sensing elements for use in the control of jet engines, J. Research NBS 45, 292 (1950) RP2136.

Washington, February 16, 1951. 